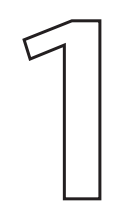

\title{
Exploratory Talk for Learning
}

\section{Douglas Barnes}

\section{Summary}

Barnes begins by outlining a 'constructivist' view of the nature of learning, and explores its implications for teaching, including the idea that coming to terms with new knowledge requires 'working on understanding' which can most readily be achieved through talk. Two kinds of talk, 'exploratory' and 'presentational', contribute to learning, but each has a different place in the sequence of lessons. Since learning in schools is a social activity, the discussion of learning moves from the individual to the group. A distinction is made between 'school knowledge' and 'action knowledge', and teachers are advised to consider whether their pupils' conception of the nature of learning is appropriate. The chapter concludes with the discussion of some practical implications for teachers.

\section{Q $_{\cap}$ For Discussion}

1 What are the main elements in the view of learning called 'constructivism'?

2 How must these elements be modified to take account of a 'social constructivist' perspective?

3 What are the practical implications for teaching these views of learning?

4 How can 'exploratory' and 'presentational' uses of language in lessons be distinguished from one another? At what point in a scheme of teaching is each likely to be appropriate?

5 In what ways can some pupils' preconceptions about the nature of learning prove to be unproductive? What might be done about this?

6 In what ways might the distinction between 'school knowledge' and 'action knowledge' be relevant to teachers in their work? 
In this chapter I shall summarise something of what I have learnt from my years as a schoolteacher and as a researcher about how pupils learn in school and how teachers can best help them. During my years in the University of Leeds I set out to investigate what role spoken - and written - language can at best play in young people's learning in classrooms and laboratories, though later on I came to define the issues less in terms of language and more as the kinds of access to the processes of learning that teachers made possible. The communication system that a teacher sets up in a lesson shapes the roles that the pupils can play, and goes some distance in determining the kinds of learning that they engage in. Thus I shall deal not only with pupils' learning but also with what teachers do to influence this. I want to acknowledge, however, that a teacher's attention is not given solely to the content of what is being taught; it is also necessary to manage social relations in the classroom, and failure in this latter respect will endanger any progress in learning. The management of these two responsibilities - which can at times seem almost to be in conflict - is central to the skill of teaching.

My own years as a schoolteacher have taught me that learning is never truly passive. One often hears the phrase active learning used with approval, so it is worth considering what exactly is being approved. When is learning active, and what processes does active learning include? Being 'active' does not imply moving about the room or manipulating objects (though either of these might be involved), but rather attempting to interrelate, to reinterpret, to understand new experiences and ideas. Whatever teaching method a teacher chooses question and answer, guided discovery, demonstration or something else - it will always be the pupil who has to do the learning. He or she will make sense of the lessons only by using the new ideas, experiences or ways of thinking in order to reorganise his or her existing pictures of the world and how it can be acted upon. This is partly a matter of relating the new ideas to what a learner already knows. It is only the learner who can bring the new information, procedures or ways of understanding to bear upon existing ideas, expectations and ways of thinking and acting. That is, the learner actively constructs the new way of understanding.

The central contention of this view of learning, which is nowadays called 'constructivism', is that each of us can only learn by making sense of what happens to us in the course of actively constructing a world for ourselves. One implication of this is that learning is seldom a simple matter of adding bits of information to an existing store of knowledge - though some adults will have received that idea of learning from their own schooling. Most of our important learning, in school or out of it, is a matter of constructing models of the world, finding out how far they work by using them, and then reshaping them in the light of what happens. Each new model or scheme potentially changes how we experience some aspect of the world, and therefore how we act on it. Information that finds no place in our existing schemes is quickly forgotten. That is why some pupils seem to forget so easily from one lesson to the next: the material that was presented to them has made no connection with their models of the world. This implies that retrieving and transforming what we already know is a crucial part of learning. 
It was Piaget who pointed out that new knowledge and experience can be assimilated when they fit comfortably into our existing schemes for understanding the world, but that other new ideas, that do not fit, force us to accommodate them by changing our schemes (Piaget and Inhelder, 1969). So some new ideas, experiences or information will require a radical revision of some part of our view of the world, and this we sometimes resist. To take one classroom example. When a teacher passed a beaker of cold water through a Bunsen flame, many of his pupils thought the droplets of water that appeared on it had either condensed from the air or spilt over the edge, both of these being familiar ideas. It required a major accommodation of their ideas about the relationship of water and fire to take in the idea that these droplets were a chemical product of the burning of the coal gas. Much of school learning requires an equally radical revision of our pictures of the physical or social world and how it works.

Since we learn by relating new ideas and ways of thinking to our existing view of the world, all new learning must depend on what a learner already knows. When we are told something we can only make sense of it in terms of our existing schemes. A child who has had no experience of blowing up balloons or pumping up bicycle tyres will make much less sense of a lesson on air pressure, however clearly it is presented, than a child who has had such experience. Most learning does not happen suddenly: we do not one moment fail to understand something, and then the next moment grasp it entirely. To take another example, compare a child's understanding of electricity with that of an adult. A child may well use the word correctly, but may lack the ability to analyse and explain, as well as to make links with those purposes and implications which make electricity important. The difference between the child and the adult will be even more marked for those who have studied physics. Most of our systems of ideas - call them schemes, frames, models, or concepts - go through a history of development in our minds, some of them changing continually throughout our lives.

The constructivist view of learning carries with it a radical requirement for teachers since it implies that their central task is to set up situations and challenges that will encourage their pupils to relate new ideas and ways of thinking with existing understandings and expectations in order to modify them. I find it useful to think of this as working on understanding. Working on understanding is, in essence, the reshaping of old knowledge in the light of new ways of seeing things. (Of course, 'seeing' here is a metaphor for various ways of symbolising, not just visual ones.) Only pupils can work on understanding: teachers can encourage and support but cannot do it for them. In this reshaping, pupils' 'old' knowledge is as important as the new experiences that are to challenge it. It is this challenge that provides the dynamic for the accommodation, the changing of previous ways of understanding for new ones. Adults and children alike are not always ready to make such adjustments and sometimes cling to views of the world that are familiar but are also ineffective or even untrue. It can be uncomfortable to have to change our ideas about how things are or how we should behave or interpret the world about us.

There are various ways of working on understanding, appropriate for different kinds of learning. Teachers commonly ask pupils to talk or write in order 
to encourage this, but drawings and diagrams, numerical calculations, the manipulation of objects, and silent thought may also provide means of trying out new ways of understanding. At the centre of working on understanding is the idea of 'trying out' new ways of thinking and understanding some aspect of the world: this trying out enables us to see how far a new idea will take us, what it will or will not explain, where it contradicts our other beliefs, and where it opens up new possibilities.

The readiest way of working on understanding is often through talk, because the flexibility of speech makes it easy for us to try out new ways of arranging what we know, and easy also to change them if they seem inadequate. Not all kinds of talking (or writing) are likely to contribute equally to working on understanding. A great deal of the writing that goes on in school is a matter of imitating what other people have said or written, and the same is true at least in part of the talk.

It is clearly important to consider what kinds of discussion contribute most to working on understanding. When young people are trying out ideas and modifying them as they speak, it is to be expected that their delivery will be hesitant, broken, and full of dead-ends and changes of direction. This makes their learning talk very different from a well-shaped presentation such as a lecture. For this reason I found it useful to make a distinction between exploratory talk which is typical of the early stages of approaching new ideas, and presentational talk (Barnes, 1976/1992). Exploratory talk is hesitant and incomplete because it enables the speaker to try out ideas, to hear how they sound, to see what others make of them, to arrange information and ideas into different patterns. The difference between the two functions of talk is that in presentational talk the speaker's attention is primarily focused on adjusting the language, content and manner to the needs of an audience, and in exploratory talk the speaker is more concerned with sorting out his or her own thoughts.

I can illustrate exploratory talk by quoting a short extract from the recording that in 1970 first challenged me to think about its nature and functions (Barnes, 1976/1992). Four 11-year-old girls were talking about a poem that they had read. They were discussing what would happen if, as in the poem, a pupil fell asleep in class.

Anne: Well the teacher's bound to notice.

Beryl: Yes really ... because I mean ... I mean if ...

Carol: Or she could have gone out because someone had asked for her or something ... She probably felt really sorry for him so she just left him ... The teachers do ...

Anne: What really sorry for him ... so she'd just left him so they could stick pins in him. [Tone of horrified disbelief.]

Dinah: Oh no she probably ... with the 'whispered' ... said 'whispered' ...

Beryl: Yes.

Carol: Yes but here it says ... um ... [rustling paper] ... Oh 'Stand away from him children. Miss Andrews stooped to see.'

Beryl: $M m$. 
Anne: So you'd think that she would do more really.

Beryl: Yes ... you'd think she'd um ... probably wake ... if she would really felt sorry for ... sorry for him she'd ...

Dinah: She'd wake him.

Beryl: [continuing] ... wake him.

Carol: Oh no! .... No, she wouldn't send him home alone .... because .... nobody's ....

Anne: His mother's bad.

Although many of the contributions were disjointed and hesitant, the girls were undoubtedly sorting out their thoughts and making sense of the poem, and a few moments later arrived at an insight crucial to its understanding. The broken utterances, the changes of direction, the corrections of themselves and one another, even the disagreements, all were part of their struggle to assign meaning to the poem. The talk, for all its incompleteness, seemed to be enabling the girls to use their existing knowledge of people and behaviour to construct a meaning for the words of the poem. Soon after making this recording I began to realise that it was not only in reading literature that we need to bring existing knowledge to give meaning to what we hear or read. All understanding depends on this, whether in school or elsewhere. This encouraged me to gather material from other parts of the school curriculum that would throw light on how putting ideas into words contributes to learning.

Exploratory talk provides an important means of working on understanding, but learners are unlikely to embark on it unless they feel relatively at ease, free from the danger of being aggressively contradicted or made fun of. Presentational talk, on the other hand, offers a 'final draft' for display and evaluation: it is often heavily influenced by what the audience expects. Presentational talk frequently occurs in response to teachers' questions when they are testing pupils' understanding of a topic that has already been taught. It also occurs when anyone, child or adult, is speaking to a large or unfamiliar audience. Such situations discourage exploration: they persuade the speaker to focus on getting it right, on 'right answers' - providing expected information and an appropriate form of speech.

Much of the talk that teachers invite from pupils is presentational in nature, and it is not my intention to deny the value to learners of having to order ideas and present them explicitly to an audience. Teachers should, however, consider at what point in the sequence of learning this should take place. In my view many teachers move towards presentational talk (and writing) too soon, when pupils are still at the stage of digesting new ideas. In the earlier stages of a new topic, it is likely to be exploratory talking and writing that will contribute more to the interrelating of old ways of thinking and new possibilities: in other words, they will be more likely to enable learners to 'work on understanding'. Requiring presentational reports, spoken or written, before pupils have come to terms with new ideas is to ask for confused speech or writing. Both presentational and exploratory talk are important in learning. Teachers need to be sensitive to the differences between them and use them appropriately. 
In teaching both adolescents and adults I made much use of small-group discussion as an element in an overall pattern of learning, partly because it makes it more likely that a larger proportion of a class will be actively involved in thinking aloud. However, I do not want to over-emphasise small groups in spite of the role they played in my investigations. I was often more interested in finding out how young people use talk as a tool of thinking in the absence of adult guidance than in recommending small-group methods. It is important not to allow ourselves to idealise group discussion: it is a valuable resource in a teacher's repertoire but it is not a universal remedy. Not all group discussions are as successful as the poem discussion quoted above: the very presence of a researcher with a tape-recorder encourages young people to put on a show. Group discussion should also never be seen as a laisser faire option. Successful group work requires preparation, guidance and supervision, and needs to be embedded in an extended sequence of work that includes other patterns of communication. With new classes some instruction in the ground rules may be needed. (Neil Mercer and Lyn Dawes in this volume discuss an approach called 'Thinking Together' intended for this purpose, and Courtney Cazden describes an approach called 'Fostering a Community of Learners' which had been strikingly successful.) By early adolescence some young people have already developed considerable social abilities, no doubt from sharing in the life of a family and the activities of other groups as well as from school. However, the ability to think aloud and to share thoughts with others is not universal, and is not necessarily linked to academic intelligence. Some young people need help to develop these skills and even to discover what discussion is.

I do not want to seem to suggest that class discussions led by the teacher are less important than group work. On the contrary, they are essential. It is important, however, for teachers to make it possible for pupils to think aloud even when they are talking with the whole class. This is difficult, as every teacher knows, since in a lively class the competition to hold the floor will discourage extended speech. Moreover, pupils competing for attention do not always listen to and reply to one another's contributions, and it is part of the task of the skilled teacher to persuade them to do so. There are other problems as well. One unpredicted outcome of several small-scale studies of teachers in action was that it is surprisingly difficult for teachers to achieve insight into pupils' thinking merely by asking a question and listening to their brief answers (Barnes, 1976/1992). As a result, they may fail to grasp what pupils had been thinking and what would give them useful support. Thus their contribution to the discussion can sometimes be less than helpful in advancing their pupils' thinking. Teaching is by no means easy.

Setting up a supportive context for learning during lessons is central to good teaching. It is through talking over new ideas with their teachers and peers that pupils can most readily move towards new ways of thinking and feeling. Indeed, for many learners the support of a social group is essential. The term common knowledge (Edwards and Mercer, 1987; Mercer, 1995) reminds us that the construction of knowledge is essentially a social process. How teachers behave in lessons, and particularly how they receive and use their pupils' written and spoken contributions, is crucial in shaping how pupils will set about learning and therefore what they will learn. It is by the way that a teacher 
responds to what a pupil offers that he or she validates - or indeed fails to validate - that pupil's attempts to join in the thinking. In an inquiry called 'Interpretation and Transmission' I found that the way teachers interact with their pupils is closely linked to their preconceptions about the nature of the knowledge that they are teaching (Barnes and Shemilt, 1974). If they see their role as simply the transmission of authoritative knowledge they are less likely to give their pupils the opportunity to explore new ideas.

This previous paragraph illustrates an alternative tradition in the psychology of learning called social contructivism. This represents learners as essentially social beings who are being inducted into cultural practices and ways of seeing the world that are enacted by the groups to which they belong. (The social constructivist view of learning is also discussed by Frank Hardman on page xxx of this volume.) Even what we call 'first-hand experience' is partly shaped by the meanings available in the culture we take part in. Learners must indeed 'construct' their models of the world, but the models they construct are not arbitrary; the experiences on which they are based do not come from nowhere. They are responses to activities and talk that they have shared with other members of the community, many of them older. This tradition provides a useful counterbalance to what I have written in earlier paragraphs from a more individualistic (Piagetian) perspective. Exploratory talk does not provide new information. When learners 'construct' meanings they are manipulating what is already available to them from various sources, exploring its possibilities, and seeing what can and cannot be done with it.

Vygotsky (1962) was one of the first psychologists to acknowledge the role of talk in organising our understanding of the world: he would not have dissented from this social constructivist view of learning. He insisted that our ability to talk and think is in the first instance social and only later becomes individual. By participating in activities and talk, children come to make as their own the purposes, practical categories and ways of going about things that are essential to their social environment, to their families and to the other groups they belong to. Central to this learning is speech - not just the forms of words and sentences that we all learn to use, but more importantly the meanings and purposes that they represent, and the social relationships in which they are embedded. We learn to participate not only in activities but also in the meanings which inform them.

This brings us to a paradox that underlies all deliberate teaching. Our culture offers to young learners powerful ways of understanding and influencing the world, so that much learning is a matter of 'getting inside' an adult view of the world in order to use it for thinking and acting. School learning is at once social and individual. Schools provide for pupils the opportunity of partially sharing the teacher's perspective, for successful lessons build up cumulatively a set of meanings that it is the task of each pupil to make his or her own. Each must deal with new experiences that challenge existing schemes and pictures of the world, for only he or she has access to the particular preconceptions and misunderstandings which need to be reflected on and modified. One of the challenges that faces all teachers is how to help pupils to try out new ways of thinking that may be disturbingly different from what they are used to, and at the same time to give more responsibility to those learners 
to develop their own understanding of the matter. Courtney Cazden (2001:22) puts the teacher's dilemma precisely: 'How to validate a student's present meaning, often grounded in personal experience, while leading the child into additional meanings, and additional ways with words for expressing them that reflect more public and educated forms of knowledge.' Teachers teach classes but pupils learn as individuals, each constructing slightly different versions of the meanings made available during the interchanges shared by the whole class and the teacher. Both the shared construction and the individual struggle to reinterpret are essential.

Some learning in schools takes place tacitly at first. Bruner (1966) showed that we often achieve conscious control only after we have gained unreflective mastery. Edwards and Mercer (1987) illustrated how primary school teachers involve their pupils in activities and talk about them in such a way as to direct attention to the crucial features that they will need to be aware of in order to participate in similar activities. It is important that such learning should later be reflected on and made explicit. Once we have laid out clearly what we believe to be the case, we are able to look critically at our assumptions and determine whether we wish to stand by them. Reflection, including the reflection that is enabled by talk outside the event - recollected in tranquillity, as it were - seems to be an essential prerequisite for critical thinking and the modification of what we believe.

Abstractions such as 'active learning' are likely to leave many teachers asking themselves how these ideas can be enacted in lessons. When one says that learning needs to be 'active', it implies that the learner is at least as important as the teacher in determining the success of lessons. One would want students to get into the habit of asking themselves - or the teacher - questions such as the following.

If that is the case, how come so-and-so happens?

I don't get that. What do you mean by -A-?

Is - X - an example of what you're saying?

If you changed $-Y-$ (one of the elements in the statement or situation)

would you get the same result?

Is it like -Z-? (i.e. suggesting an analogy)

Questions such as these might be directly modelled by the teacher's practice during lessons, but more important would be the overall way in which ideas were presented and discussed in those lessons. The learner's preconceptions about what activities constitute 'learning' play an important part in this. Our society offers to young people various visions of what learning might be, including quiz shows, Mastermind, spelling tests, and other images which represent learning as rote memory and 'getting the right answer'. Pupils whose approach to school work is dominated by such images are likely to adopt unsuitable strategies when they are required to understand complex ideas either in science or in the humanities and social studies.

This was the central concern of a group of teachers in one Australian secondary school who decided that their pupils' preconceptions about learning were 
proving a major barrier. One teacher found that pupils came in and automatically copied into their notebooks whatever was on the blackboard, whether or not it was relevant or even made sense. A teacher of English, trying to encourage pupils to approach all stories with imagination, understanding and insight, was faced by pupils who wanted her to write down her questions about one particular story and provide answers so that they could learn them by heart. Clearly they had no idea of what was required. Science teachers found that pupils were memorising the words of scientific principles, instead of trying to understand them, and similarly throughout the curriculum. These teachers set up in their school a Project for Enhancing Effective Learning (PEEL), trying out various ways of helping their pupils to understand what kind of learning is required by a modern curriculum as a way of making them more effective learners (Baird and Mitchell, 1986). They were much helped in this by John Baird, who had previously carried out research into how highly intelligent and successful adult learners set about learning. He found that good adult learners, instead of narrowly committing information to memory:

1 relate new ideas, experiences and information to a wide range of existing knowledge and experiences;

2 look critically at these relationships, noticing where there are matches or discrepancies, and asking questions about these;

3 realise which parts of the new they have not fully grasped, think through the implications, and look for examples and counter-examples.

That is, they actively try to make sense of what they are learning, and relate it to what they already know and understand. This helped the PEEL teachers to decide what practical measures they should adopt to improve their students' learning. These included:

- having students write about and discuss what they already know of the topic;

- getting them to predict; 'What do you think would happen if .....? Why?';

- encouraging the asking of 'good questions' i.e. those that seek underlying principles;

- setting up frequent occasions for interpretive discussion;

- teaching the making of notes through collaborative discussion;

- encouraging students occasionally to list what they understand and what they do not yet understand;

- at times, allowing students to negotiate learning tasks.

Students can be encouraged to contribute examples, make connections with their own experience, and discuss areas where the new material seems to clash with what they thought to be the case. Discussion and explanation by the pupils should be a central part of lessons, and this should also include the producing and evaluating of supportive evidence. Pupils should be expected to ask questions as well as to answer them; their questions not only engage them in productive thinking but can provide valuable information to the teacher about their level of comprehension. They should learn also that some questions are 
more productive than others. They should be encouraged to raise problems, to propose anomalies, and to look for contexts in which the new ideas do not seem to apply as well as those in which they seem to be useful.

It is not easy to spell out in greater detail what this strategy amounts to since it depends in part on the material being taught and on the pupils, and often on contextual influences that are outside of a teacher's control. A few general suggestions can however be made. The provision of useful material for discussion demonstrations, apparatus, maps, pictures, texts - and a habit of inviting pupils to predict and justify their predictions will let them know that thinking aloud is valuable. Teachers' questions that open lines of thought are more valuable than those which require bits of information. Listening to and reading attentively what pupils say or write, and validating their attempts to understand by replying to them, are important: teachers sometimes automatically assess when they would do better to reply. When written work is set there should often be explicit discussion of the criteria by which it is to be assessed.

When my students and I first tape-recorded lessons, we were all surprised at how much talking teachers did and the short time left for pupils' answers. We were also amazed by the pupils' passivity: they seemed not to be engaging with the ideas being presented to them (Barnes, 1969). The question and answer routine (often called 'recitation' in the USA, and 'IRF' in several chapters of this book) performs the function of managing the class and holding their attention but it does not easily give opportunities for pupils to work on understanding through talk. Well managed, it can enable a teacher to lead a class through a complex sequence of thought, but then each pupil needs to recreate the sequence in his or her own terms. More recent commentators have insisted that IRF teaching is essential, and have shown how it can lead to developed discussion and not merely a recapitulation of authoritative material (Wells, 1993; Cazden, 2001: 41; Alexander, 2004).

Since our culture provides misleading models, it is useful to engage pupils in an explicit discussion of what learning requires of them. They should be encouraged to take an active responsibility for the progress of their learning, to identify areas of uncertainty and confusion and look for help with them. Teachers in the PEEL project found it helpful to have pupils evaluate their own strategies for learning, which was possible because they had previously discussed what constituted good learning. In effect, since learners are best placed to map the progress of new understanding, it is they who should identify what help they need. The overall purpose should be to hand over to pupils more responsibility for their own learning, by requiring them to think about it and by avoiding the mere rehearsal of inert information.

It has perhaps become too much a truism that learning is more effective when a learner perceives that what is being learnt is relevant to his or her life, though it also remains true that some young people are more likely to struggle to make sense of new experiences when these are important in their own lives. However, Phil Scott on page Xxx of this volume argues persuasively that there are occasions when pupils can be persuaded to recognise the interest and challenge of subject matter they had not previously thought about. When young people feel that what is being taught in school is neither interesting nor relevant to their present and future lives they will at best receive it superficially. By 'superficially' I mean 
that the knowledge - of whatever kind - will not be integrated into the learner's picture of the world as he or she experiences it. In contrast, knowledge that has been integrated will have the capacity to affect how he or she thinks, feels and acts, in school or elsewhere. I found it useful to label this distinction school knowledge versus action knowledge (Barnes, 1976/1992). New knowledge is all the more powerful if it is provided just at the moment when learners realise that they need it to solve a problem or answer a question. Knowledge that answers a question that has not yet been asked will soon be forgotten. Part of a teacher's task in managing learning is the provoking of a questioning habit of mind, seeing to it that their pupils perceive that there is a question to be answered before they head them towards the material that can be used to answer it.

Too much of what is taught in school remains 'school knowledge', divorced from pupils' lives and remaining at the surface of the mind, never penetrating to any depth. When boys and girls relate new ideas to their lived-in world this is one aspect of what I mean by 'working on understanding', but of course their lived-in world is not merely the world of everyday incidents. Courtney Cazden in pages $\mathrm{xxx}-\mathrm{xxx}$ of this volume shows how powerfully a social context for learning that empowers the learners by involving them in inquiry can generate interest in new material as well as satisfaction in the quality of their own participation.

As the years passed I became more and more convinced that learners should be given more access to the grounds upon which the knowledge they were learning was based. Knowledge is too often presented as if it is beyond challenge and beyond the examination of alternatives. Tasks are often set without teachers indicating in terms that learners can understand what criteria will be used to judge success or failure. I am convinced not only that conscious participation in learning is essential, but also that in order to achieve active learning learners should be encouraged to be reflective and critical. These concepts mark the culmination of what I have written in this chapter. They imply that every school pupil should eventually take deliberate responsibility for learning and its relationship to the world of understandings, beliefs and values that he or she inhabits. Reflection includes taking responsibility for finding connections and examples, asking questions, reinterpreting experience, and searching for new techniques and new ways of understanding relevant to the matter in hand. 'Critical' learning goes further and implies that teachers should encourage pupils to find alternative ways of looking at topics, and should help them to grasp what evidence may be used to support one or another viewpoint. The purpose is to prepare for life outside school by giving pupils the opportunity to make informed choices, and to prepare them as future adults to become full participants in their own lives.

\section{References}

Alexander, R. (2004) Towards Dialogic Teaching: Rethinking Classroom Talk. Osgoodby, North Yorkshire: Dialogos.

Baird, J.R. and Mitchell, I.J. (eds) (1986) Improving the Quality of Teaching and Learning: An Australian Case Study. Clayton, Victoria: Monash University Faculty of Education. 


\section{EXPLORING TALK IN SCHOOLS}

Barnes, D. (1969) 'The language of the secondary classroom', in D. Barnes, J.N. Britton and $\mathrm{H}$. Rosen (eds), Language, the Learner and the School. Harmondsworth: Penguin. Barnes, D. (1976/1992) From Communication to Curriculum. London: Penguin. (Second edition, 1992, Portsmouth, NH: Boynton/Cook-Heinemann.)

Barnes, D. and Shemilt, D. (1974) 'Transmission and interpretation', Educational Review, 26: 3. (Reprinted in Language Perspectives (1982) B. Wade (ed.). London: Heinemann.) Bruner, J.S. (1966) Toward a Theory of Instruction. Harvard: Belknap.

Cazden, C.B. (2001) Classroom Discourse: the Language of Teaching and Learning. Portsmouth, NH: Heinemann.

Edwards, D. and Mercer, N. (1987) Common Knowledge: The Development of Understanding in the Classroom. London: Methuen.

Mercer, N. (1995) The Guided Construction of Knowledge: Talk Amongst Teachers and Learners. Clevedon: Multilingual Matters.

Piaget, J. and Inhelder, B. (1969) The Psychology of the Child. London: Routledge and Kegan Paul.

Vygotsky, L.S. (1962) Thought and Language. Cambridge, MA: MIT.

Wells, G. (1993) 'Reevaluating the IRF sequence', Linguistics and Education, 5: 1-37. 